\title{
Crítica e coalizão: repensar a resistência com Foucault e Butler
}

\section{Critique and coalition: rethinking resistance with Foucault and Butler}

\section{Critique et coalition : repenser la résistance avec Foucault et Butler}

\author{
André Duarte, Maria Rita de Assis César*
}

Universidade Federal do Paraná (UFPR), Curitiba, PR, Brasil

\section{Resumo}

Discutimos a importância e o significado de algumas noções-chave do pensamento de Michel Foucault e de Judith Butler, como as noções de "atitude crítica" e de "políticas de coalizão", tendo em vista repensar o estatuto da noção e da própria prática da resistência, no contexto das lutas dos movimentos sociais de caráter identitário, vinculadas às demandas de populações marginalizadas (pessoas negras; mulheres; LGBTs). Essa discussão nos permite estabelecer uma relação entre a crítica e a resistência no pensamento de Foucault, bem como nos permite relacionar estes aspectos centrais do pensamento foucaultiano à reflexão política pós-identitária de Judith Butler. Por sua vez, a associação de noções de crítica, resistência e políticas de coalizão nos permite propor uma avaliação crítica dos embates fratricidas entre militantes de diversos movimentos

\footnotetext{
*AD: Doutor em Filosofia, e-mail: andremacedoduarte@yahoo.com.br

MRAC: Doutora em Educação, e-mail: mritacesar@yahoo.com.br
}

Rev. Filos., Aurora, Curitiba, v. 31, n. 52, p. 32-50, jan./abr. 2019 
sociais, cuja ênfase em concepções identitárias rígidas tem promovido o enfraquecimento dos próprios sujeitos da resistência.

Palavras-chave: Foucault. Butler. Crítica. Resistência. Coalizão.

\section{Abstract}

We shall discuss the importance and the meaning of some of Michel Foucault's and Judith Butler's key-notions, such as "critical attitude" and "coalition politics", in order to reconsider the very meaning of resistance, both conceptually and as a political practice, in the context of identitarian social movements fighting for the demands of marginalized populations (black people; women; LGBTs). Along this discussion, we shall connect the notions of resistance and critique in Michel Foucault's thinking, and we shall also relate those notions to Butler's post-identitarian understanding of coalition politics. By connecting critique, resistance and coalition, we aim to critically evaluate the violent confrontations that have recently opposed political militants whose rigid identitarian conceptions have been promoting the weakening of the very subjects of resistance.

Keywords: Foucault. Butler. Critique. Resistance. Coalition.

Tomando como ponto de partida algumas noções-chave de Michel Foucault e de Judith Butler, procuramos refletir criticamente sobre o recrudescimento das querelas identitárias entre integrantes dos movimentos ou coletivos negro, feminista e LGBT no Brasil contemporâneo. A partir de uma interpretação circunstanciada de algumas reflexões de Butler e de Foucault, estabelecemos uma conexão teórica entre as noções de atitude crítica, resistência e políticas de coalizão, e avaliamos criticamente as crescentes confrontações de natureza identitária entre militantes dos referidos movimentos e coletivos, cujas divisões e facções tendem a enfraquecê-los ao sabor da multiplicação de discursos e práticas fundados no ódio e na desconfiança mútuos.

Parece-nos preocupante o atual acirramento dos conflitos entre militantes dos movimentos e coletivos de populações historicamente 
marginalizadas e subalternizadas no Brasil: a cada dia, as redes sociais testemunham e promovem uma verdadeira contenda entre ativistas que parecem querer se afirmar como os únicos detentores do direito de falar e agir em nome de determinada coletividade social. Intensificamse também as discórdias em torno da definição do vocabulário no qual devem ser expressas publicamente as demandas dos diferentes coletivos e movimentos sociais minoritários. De modo geral, tais disputas giram em torno de definições identitárias que autorizariam a tomada de palavra, certificariam a correção do vocabulário e concederiam o direito de agir e falar como legítimo/a representante de tal ou qual movimento social, coletivo ou parcela da população. Mensagens disseminadas nas redes sociais dão-nos a impressão de que haveria uma disputa no seio das categorias sociais mais desfavorecidas e marginalizadas para saber quem portaria consigo os signos de maior subalternidade, os/as quais autorizariam alguém a falar e agir em nome das categorias sociais que se pretende representar. Se é claro que são saudáveis os debates entre participantes de movimentos sociais, a situação se torna preocupante quando assistimos à formação de campanhas de vigilância discursiva e à multiplicação de ameaças e reprimendas públicas que visam cercear ou controlar a expressão alheia. Torna-se cada vez mais frequente que jovens militantes se voltem contra lideranças experientes e tradicionais, acusando-os/as de não estarem mais à altura das demandas contemporâneas dos movimentos que eles/elas ajudaram a criar. Também ocorre que, no decurso dessas querelas, indivíduos ou grupos se vejam excluídos de espaços comuns de discussão e atuação política, frequentemente sob o crivo de acusações graves, jamais devidamente provadas. Numa palavra, não é infrequente que os/as militantes de movimentos sociais e coletivos contra a discriminação acabem por promover novas formas de violência interna, ampliando o espectro de opressões e microfascismos que eles pretendiam combater ${ }^{1}$.

\footnotetext{
Segundo Richard Miskolci (2017), "Se o fascismo incorporou as análises sobre conflitos sociais baseadas em classes, distorcendo-as a ponto de autodenominar-se, na Alemanha nazista, de nacional-socialismo, não é de causar surpresa que 0 microfascimo contemporâneo beba nas discussões sobre diferenças achatando-as ao identitarismo belicoso". Veja-se "Notas sobre o microfascismo nas redes sociais". Revista Cult, 3 de março de 2017. Disponível em: <https://revistacult.uol.com.br/ home/redes-de-ressentimento-notas-sobre-0-microfascismo-nas-redes-sociais/>. Acesso em: 07/02/2018.
} 
No círculo desses movimentos sociais e coletivos de minorias anti-hegemônicos repete-se à exaustão o discurso acerca da resistência. Por certo é preciso resistir ao crescimento do conservadorismo, do fundamentalismo e dos comportamentos de natureza fascista no Brasil atual. Porém, o que queremos dizer quando nos afirmamos como resistentes? O que significa resistir e, sobretudo, o que a resistência exige de nós enquanto resistentes? Mesmo se concordarmos com Butler e com Foucault e não exigirmos dos/as resistentes que definam a priori as condições teóricas destinadas a garantir que não haja equívocos e desvios nos seus atos e palavras, resta ainda perguntar: será que refletimos suficientemente sobre o que constitui a especificidade dos atos e palavras de resistência? Será que nos basta pensar a resistência como conjunto de atos e palavras que apenas dizem 'não' a toda e qualquer forma de governamento? Em suma, enquanto resistentes, de que forma podemos evitar reproduzir as violências e discriminações que nossos atos e palavras de resistência pretenderiam combater a justo título?

É neste contexto turbulento e exasperante que recorremos a algumas noções capitais de Foucault e de Butler, tendo em vista repensar o sentido da resistência. Quanto a Foucault, argumentamos que haveria um sutil deslocamento entre sua noção genealógica de "resistência", formulada em meados dos anos 70, e suas noções posteriores a respeito da "estética da existência" e das "práticas refletidas de liberdade", datadas do final dos anos 70 e início dos anos 80 . Nossa hipótese é que esse deslocamento na noção de resistência estaria associado à importância crescente assumida pela noção de crítica no pensamento foucaultiano a partir de finais dos anos 70. Ao se associar à noção de crítica, a resistência deve ser entendida como um conjunto de práticas de liberdade, isto é, como exercícios e experiências críticas de autotransformação e de transformação dos outros, com os quais interagimos politicamente. Pensamos que essa reconsideração do sentido das lutas de resistência, em associação com as noções foucaultianas de crítica e de práticas refletidas de liberdade visando a transformação de si e dos outros, forja uma alternativa política e teórica para o clima belicoso instaurado entre os/as militantes dos coletivos e movimentos sociais de minorias. Tais conflitos parecem girar em torno de uma 
rígida concepção da resistência, entendida como rejeição de toda forma de governamento e de interação com aqueles que não pensam e agem como eu/nós. Essa concepção rígida da resistência leva a um radicalismo cego, segundo o qual somente haveria uma única forma de resistir às estratégias de captura dos poderes. Por outro lado, se compreendermos a resistência como relacionada ao trabalho da crítica, isto é, enquanto trabalho refletido da liberdade sobre si mesmo e sobre os outros, visando diagnosticar os múltiplos efeitos das relações de poder sobre os sujeitos, então ela exigirá dos/as resistentes a capacidade de se descentrar, de se transformar, de não permanecer sendo sempre os/ as mesmos/as. A maneira como Foucault e Butler compreendem a noção de crítica nos parece bastante oportuna neste contexto, pois ambos a consideram como exercício cotidiano associado ao engajamento em discursos e atos de resistência, e não como doutrina teórica prévia ou desligada do contexto político imediato. Finalmente, gostaríamos de propor a hipótese de que a crítica, assumida e exercida como exercício cotidiano e renovado a cada luta de resistência, pode e deve se conectar com a concepção de Judith Butler acerca das lutas políticas organizadas segundo o modelo da coalizão aberta entre diferentes movimentos minoritários, de modo a favorecer a formação de alianças políticas não fundadas em rígidas concepções de identidade.

\section{A resistência em Foucault: tensões e deslocamentos}

O termo "resistência" é certamente importante no cômputo do projeto genealógico desenvolvido por Foucault ao longo dos anos 70, culminando na publicação de Vigiar e Punir, de 1975, e do primeiro volume de História da Sexualidade, A vontade de saber, de 1976. No entanto, uma leitura atenta dessas obras maiores mostra que o autor não concedeu excessiva importância teórica à noção de resistência, nem tampouco se deteve em análises minuciosas a seu respeito. Não casualmente, durante os anos 70 e 80, Foucault foi muitas vezes criticado como um teórico dos poderes contra os quais não haveria como resistir, como observou Edgardo Castro (2009, p. 387). De fato, Foucault pouco se deteve 
sobre a noção de resistência em Vigiar e Punir e, quando a mencionou, ele o fez de maneira pouco elucidativa, sem conceituá-la teoricamente. De fato, o termo aparece apenas em dez páginas do livro. Já em um momento bastante avançado do livro, Foucault menciona que o Panóptico não deve ser como um "edifício onírico", mas como o "diagrama de um mecanismo de poder conduzido à sua forma ideal; seu funcionamento, abstraindo-se de qualquer obstáculo, resistência ou desgaste, bem como pode ser representado como um puro sistema arquitetural e ótico [...]" (1975, p. 207). Pouco adiante, Foucault afirma que o que é próprio das disciplinas é definir uma "tática de poder" que responde à exigência de suscitar o mínimo possível de "resistência" (1975, p. 220), fazendo com que o exercício do poder se torne "menos custoso, tanto do ponto de vista político como econômico". Na página seguinte, o autor prossegue na mesma linha argumentativa e afirma que a disciplina se destina a resolver problemas que antigas formas de poder não foram capazes de solucionar adequadamente, dentre os quais se menciona a exigência de "neutralizar os efeitos de contra-poder que nascem daí e que formam resistência ao poder [...]: agitações, revoltas, organizações espontâneas, coalizões - tudo o que pode provir de conjunções horizontais" (1975, p. 221). Uma última menção à noção de resistência em seu caráter articulado ao exercício dos poderes disciplinares surge na afirmação de que a "produção da delinquência" e seu investimento pelo "sistema policial-penal" jamais "deixou de encontrar resistências", visto que suscitou "lutas e provocou reações" (1975, p. 291).

Já no primeiro volume da História da sexualidade, Foucault é mais generoso em suas explicações sobre a noção de resistência, mas, mesmo ali, suas análises tampouco se alongam ou se aprofundam suficientemente. Ao discutir o caráter relacional e de não-exterioridade entre poder e resistência, Foucault anuncia a célebre tese de que "ali onde há poder, há resistência" (1976, p. 125). Sendo assim, ao reforçar o caráter relacional existente poder e resistência, Foucault reitera que os poderes somente existem e se exercem "em função de uma multiplicidade de pontos de resistência: eles desempenham nas relações de poder o papel de adversário, de alvo, de apoio, de projeção para uma captura. Esses pontos de resistência estão presentes em toda parte da 
rede de poder" (1976, p. 126). Haveria uma multiplicidade de relações de poder e, assim, também uma multiplicidade de pontos de resistência, sem que houvesse um único foco privilegiado da rebelião, da revolta ou da revolução. A noção de resistência deve ser compreendida em seu caráter plural, no sentido de que não existe "a" resistência, mas apenas resistências "possíveis, necessárias, improváveis, espontâneas, selvagens, solitárias, concertadas, agressivas, violentas, irreconciliáveis, abertas à negociação, interessadas ou sacrificiais; por definição, só podem existir no campo estratégico das relações de poder" (1976, p. 126). As resistências são definidas, então, como "o outro termo nas relações de poder; elas se inscrevem nas relações de poder como seu vis-à-vis irredutível" (1976, p. 127). Do mesmo modo como o poder se exerce de maneira móvel e tática, também as resistências se deslocam e se transformam conforme as circunstâncias. Em consonâncias com essas teses, Foucault também argumentava que não se deveria propor uma análise jurídica ou moral das relações entre poder e resistência, mas que o importante era analisar a dinâmica de exercício do poder e da resistência em contextos espaço-temporais bem definidos.

Rebatendo os críticos que já por ocasião da publicação das duas obras maiores de seu projeto genealógico o acusavam de ser um filósofo do poder, desatento às formas da resistência, Foucault concede uma entrevista em 1977 na qual se explica: “Quero dizer que as relações de poder suscitam necessariamente, convocam a cada instante, abrem a possibilidade para uma resistência, e é porque há possibilidade de resistência, de resistência real, que o poder daquele que domina procura se manter, e isso com tanto mais força, com tanto mais astúcia, quanto maior é a resistência" (1994a, p. 407). Nesta mesma entrevista, Foucault também sublinhava sua compreensão das relações de poder como "relações de força, de confrontações, portanto, sempre reversíveis", ao mesmo tempo em que também enfatizava a "luta perpétua" entre poder e resistência (1994a, p. 407). Ele nos dava a entender que haveria uma espiral entre poder e resistência, os quais se entrelaçariam sem ponto de chegada. Nesta linha de raciocínio, quando Foucault definiu a sexualidade como um "dispositivo histórico", ele associou, lado a lado, 
os efeitos de captura e de assujeitamento dos poderes disciplinares ao processo de "reforço dos controles e das resistências" (1976, p. 139).

Em outras passagens, contudo, Foucault também sugeriu haver uma possível distinção entre "efeitos (de assujeitamento ou de resistência”) (1976, p. 153; grifo nosso). Essa possível distinção entre efeitos de sujeição oriundos de um determinado dispositivo de poder e as figuras historicamente correlatas da resistência parece ser retomada na célebre afirmação foucaultiana de que, "Contra o dispositivo de sexualidade, o ponto de apoio de contra-ataque não deve ser o sexo-desejo, mas os corpos e os prazeres" (1976, p. 208). Foucault parece propor que, a despeito do entrelaçamento histórico entre poder e resistência, seria possível distinguir entre diferentes figuras históricas da resistência, de maneira que o apelo aos corpos e aos prazeres, em seu caráter múltiplo, criativo e aberto a experiências coletivas de desassujeitamento, deveria assumir precedência sobre as formas da resistência que, ao se apoiarem sobre as figuras da interpretação do sexo e do desejo, nada mais fariam senão reforçar estratégias de assujeitamento promovidas no interior do dispositivo histórico da sexualidade. Pode-se então perguntar: as relações entre poder e resistência se desenvolveriam segundo o modelo do entrelaçamento em espiral e luta infinita, de maneira que não seria possível distinguir qualitativamente entre o que provém da ordem do poder e aquilo que provém da ordem de uma resistência efetiva ou eficaz, capaz de abrir fissuras num dispositivo de poder-saber? Haveria espaço no pensamento de Foucault para a consideração de uma resistência que efetivamente contasse como resistência, isto é, que pudesse fraturar o interior de um determinado dispositivo de poder-saber, não sendo, portanto, apenas mais uma etapa na luta infinita que entrelaça poder e resistência, ambos sendo um o vis-à-vis do outro, sem que pudéssemos distingui-los entre si?

Diante dessa pergunta, Habermas tem uma resposta pronta: a história genealógica de Foucault perde de vista a dimensão crítica e fracassa na ambiguidade entre relativismo e positivismo, sendo incapaz de mostrar que alguma forma de resistência contenha em si qualquer superioridade normativa em relação ao poder contra o qual ela se enfrenta: "Todo contrapoder move-se no horizonte de poder combatido 
por ele e transforma-se, tão logo saia vitorioso, em um complexo de poder que provoca um outro contrapoder" (2000, p. 393). A despeito das críticas contra o suposto "criptonormativismo" (HABERMAS, 2000, p. 394) do pensamento de Foucault, isto é, sua suposta incapacidade para responder a perguntas simples, como: “'Por que a luta é preferível à submissão? Por que resistir à dominação?"' (HABERMAS, 2000, p. 397), não pensamos que nosso autor tenha permanecido ambíguo ou equívoco a respeito das relações entre poder e resistência, nem durante suas investigações genealógicas, nem muito menos durante suas últimas pesquisas ético-políticas. Se Foucault de fato não concebeu a existência de exterioridades entre poder e resistência, os quais se confrontam sempre num mesmo solo histórico, isto não significaria que poderes e resistências fossem absolutamente idênticos ou indiscerníveis entre si, de maneira que toda e qualquer resistência somente poderia aumentar o próprio poder que ela pretendia confrontar, invertendo-se apenas a hierarquia entre os contendores. Por certo, tal fenômeno pode muito bem ocorrer, e talvez seja exatamente aquilo que ocorra o mais frequentemente. Os confrontos e agressões entre os/as próprios/as resistentes, situação problemática à qual nos referimos no início deste texto, bem poderiam exemplificar essa situação pela qual os atos de resistência ao poder se valem dos mesmos mecanismos de poder que pretendiam criticar, tendo em vista suplantar tal poder e instalar em seu lugar uma nova formação de poder. No entanto, essa não parece ser a última palavra de Foucault a respeito das relações entre poder e resistência, nem no âmbito de sua reflexão genealógica, nem muito menos em sua derradeira reflexão ético-política, como veremos mais a seguir. No âmbito do projeto genealógico, a distinção entre duas figuras da resistência - uma que apela ao sistema "sexo-desejo" e suas artimanhas interrogativas e analíticas; outra que recorre a experiências coletivas que engajam uma multiplicidade de corpos e os prazeres - parece mostrar que, já então, Foucault não considerava que toda forma de resistência fosse apenas e simplesmente uma reversão na correlação de forças que se opõem entre si. Em sua reflexão sobre a história da sexualidade, Foucault levou em consideração tanto as resistências que reforçam as estruturas de poder contra as quais elas 
investem, fortalecendo o efeito de espiral e luta perpétua entre poder e resistência, quanto, por outro lado, afirmou a existência de resistências que se definem como práticas e discursos capazes de inventar maneiras alternativas e criativas de enfrentar e desmontar preceitos e projetos de um determinado dispositivo de poder-saber, abrindo brechas e fraturas em seu interior ${ }^{2}$. Basta reler estas duas citações cruciais, com as quais Foucault conclui o primeiro volume da sua História da Sexualidade:

É da instância do sexo que é preciso se liberar se, por meio de um retorno tático dos diversos mecanismos da sexualidade, quisermos fazer valer, contra as tomadas de poder os corpos, os prazeres, os saberes, em sua multiplicidade e em sua possibilidade de resistência (1976, p. 208).

E devemos pensar que um dia, talvez, numa outra economia dos corpos e dos prazeres, já não se compreenderá muito bem de que modo as astúcias da sexualidade e do poder que o dispositivo da sexualidade sustenta, conseguiram nos submeter a essa austera monarquia do sexo, a ponto de nos entregar à tarefa indefinida de forçar seu segredo e de extorquir a essa sombra as confissões mais verdadeiras. Ironia desse dispositivo: é preciso que acreditemos que nisso reside nossa 'liberação'"' (1976, p. 211; grifo nosso).

Contudo, este ainda não é o aspecto que mais nos interessa ressaltar aqui, pois esta distinção entre resistências que promovem o reforço dos sistemas de poder contra o qual se lançam, e resistências que fraturam a economia de poder-saber dos dispositivos no interior dos quais elas se constituem, não é certamente o ponto de chegada da reflexão de Foucault sobre o assunto. $\mathrm{O}$ argumento que nos parece importante ressaltar é o do que, pelo menos até meados dos anos 70, Foucault ainda pensava as relações entre poder e resistência predominantemente segundo o modelo bélico do enfrentamento de forças que se exercem num mesmo plano ou solo histórico, provocando efeitos de reversão ou

2 Discutimos em maior detalhe essa distinção entre figuras da resistência que apelam ao que Foucault denominou como "sexo-rei" e seu séquito de interpretações e interrogações acerca do próprio desejo, e figuras da resistência que recorrem à experiência da multiplicidade dos corpos e da capacidade de deles extrair prazer no nosso texto: "Inútil resistir ao dispositivo da sexualidade? Foucault e Butler sobre corpos e prazeres." In Revista de Filosofia Aurora online, v. 28, p. 947-967, 2016. 
de curto-circuito entre si. Ora, nos parece que este modelo agonístico bem poderia levar à compreensão, a nosso ver errônea, de que entre poder e resistência não existiria qualquer distinção qualitativa, tudo se resumindo à contenda entre partidários/as de duas posições opostas, uma sendo correlata da outra. Por outro lado, o aspecto central que pretendemos realçar é o deslocamento no modo como Foucault passa a pensar as relações de poder e resistência a partir do início dos anos 80, quando ele se afasta do modelo bélico da contraposição entre forças que se enfrentam e passa a pensar tal relação segundo o modelo mais flexível do governamento, isto é, como "uma relação na qual um tenta dirigir a conduta do outro" (1994b, p. 720). O corolário interessante e inovador dessa nova forma de conceber as relações entre poder e resistência, agora segundo o modelo do governo (dos outros, mas também de si mesmo), é o de que "somente pode haver relações de poder na medida em que os sujeitos são livres", de modo que "se há relações de poder por todo o campo social, é porque há a liberdade em toda parte" (1994b, DE IV, p. 720). Tal conclusão simplesmente não se encontrava enunciada nos trabalhos da fase genealógica de Foucault, nos quais a noção de liberdade não assumia tão importante relevo. O que teria permitido a Foucault introduzir a noção de liberdade no contexto de sua reflexão sobre as relações entre poder e resistência?

O assunto é complexo e requer uma avaliação pormenorizada acerca dos deslocamentos teóricos promovidos pela introdução das noções de governo e de governamentalidade no léxico foucaultiano a partir do curso de 1978, Segurança, Território, População, assunto que abordamos em textos anteriores (DUARTE, 2015; 2010). Aqui, a hipótese que gostaríamos de formular é a de que Foucault somente pôde chegar a essa redefinição da natureza da relação entre poderes e resistências, afirmando de maneira inequívoca a liberdade dos sujeitos que resistem às artimanhas do poder em movimentos de contraconduta e em lutas transversais, após ter refletido detidamente sobre a importância da noção de "crítica", definida em uma conferência de 1978, Qu'est-ce que la critique?, enquanto atitude de insubmissão refletida e voluntária. Consideramos que a noção de crítica é um dos elementos cruciais que instaura a mutação na concepção genealógica das relações de poder-resistência, a qual 
se desloca do modelo guerreiro da contraposição das forças na direção do modelo flexível e móvel das lutas transversais e das contracondutas. No curso desse deslocamento, Foucault passará a pensar que os sujeitos das lutas transversais e dos movimentos de contraconduta são os sujeitos da crítica, isto é, aqueles que, ao resistirem, exercem sua liberdade de maneira reflexiva, transformando-se e produzindo transformações nos outros com os quais interagem politicamente.

\section{A noção de crítica no pensamento de Michel Foucault: surgimento e repercussões}

É numa conferência de 27 de maio de 1978, pronunciada na Sorbonne perante a Sociedade Francesa de Filosofia, que Foucault se detém pela primeira vez numa análise acerca da noção de crítica, tomando a reflexão de Kant em seu opúsculo Was ist Aufklärung como ponto de partida, mas certamente não de chegada. Naquela conferência Foucault definia a crítica como uma certa atitude, isto é, como

uma certa maneira de pensar, de dizer, igualmente de agir, uma certa relação para com aquilo que existe, para com aquilo que se sabe, que se faz, uma relação para com a sociedade, a cultura, também uma relação para com os outros, e que se poderia denominar, digamos, como atitude crítica (2015, p. 34).

É por meio dessa definição geral que Foucault procura desintrincar a noção de crítica da exigência teórica de oferecer critérios epistemológicos ou morais visando a prevenir os riscos e equívocos que sempre assombram o engajamento político. Esta sua recusa, por um entendimento estritamente epistemológico e/ou moral da crítica, também se manifesta em sua definição da atitude crítica como a "arte" pela qual se podem enfrentar os processos de governamentalização pelos quais os sujeitos tornam-se assujeitados "por mecanismos de poder que se reclamam de uma verdade" (2015, p. 39). A partir do momento em que Foucault faz da crítica uma questão central para seu pensamento, ele a entenderá sempre como uma certa maneira de se conduzir, aquela que 
se põe em confronto com a realidade, entendida no sentido mais amplo possível, englobando o questionamento da cultura, da sociedade, dos saberes, as ações, dos outros e, como veremos adiante, de si mesmo. Se a crítica é uma atitude e uma arte pela qual se colocam em questão as técnicas de governamentalização que buscam conduzir a conduta das populações, então ela deve ser entendida como uma contraconduta. Porém, a atitude crítica e as contracondutas não se caracterizam pela recusa absoluta de toda e qualquer forma de governo, mas pela rejeição de determinadas formas de ser conduzido e governado: "'como não ser governado desse modo, por aqueles ali, por esses princípios, em vista daqueles objetivos e por meio daqueles procedimentos, não desse modo, não por isso, não por eles'?" (2015, p. 37) Assim, a crítica será a arte de operar processos de "desassujeitamento" (désassujettissement), pois ela será o "movimento pelo qual o sujeito se dá o direito de interrogar a verdade sobre seus efeitos de poder e o poder sobre seus discursos de verdade" (2015, p. 39).

Foucault manteve sua intuição original de que não haveria exterioridade entre a crítica e a condução de condutas, bem como sua ideia acerca do caráter tópico e local de toda forma de exercício crítico e de ação de resistência. Com isso, ele parece ter pretendido afirmar que a crítica seria inerente às contracondutas e não um exercício teórico $a$ priori, desvinculado do engajamento político e de efeitos ético-políticos de transformação de si e dos outros. No entanto, o aspecto realmente importante aqui é que com a introdução da noção de crítica já não era mais suficiente pensar as relações entre condução de condutas e contracondutas segundo o modelo polêmico da confrontação e da reversibilidade na correlação de forças que se combatem. De fato, parece-nos que a introdução da noção de crítica no pensamento de Foucault opera a abertura de uma brecha de reflexividade, antes inexistente em suas considerações, por meio da qual se introduzirão algumas noções cruciais de suas pesquisas tardias, culminando na sua concepção acerca do ethos filosófico que impregna as práticas refletidas de liberdade ao longo da história ocidental, desde a estética da existência dos antigos até certos movimentos políticos dos anos 70 e 80, como o movimento gay, assunto sobre o qual Foucault se pronunciou em diversas entrevistas. 
A crítica como instância que abre uma brecha pela qual o si mesmo se torna foco de questionamento é algo que ainda não está devidamente consolidado na conferência de 1978. Entretanto, já ali a importância do retorno reflexivo sobre si mesmo se deixa entrever quando Foucault, interrogando o texto de Kant sobre o Esclarecimento, propõe uma questão que marcará o percurso de seu pensamento até o fim: "que sou eu, eu que pertenço a essa humanidade, talvez a essa franja, a esse momento, a essa humanidade que está assujeitada ao poder da verdade em geral e das verdades em particular?" (2015, p. 48-49). Seguindo essa mesma linha de questionamentos, Foucault afirma em um texto de 1979, "Por uma moral do desconforto", que a tarefa da crítica é a de pôr em questão "o que é que acaba de nos chegar? O que é este acontecimento, isto que não é nada outro do que aquilo que acabamos de dizer, de pensar, de fazer - nada outro senão nós mesmos, isto que fomos e que ainda somos? (1994a, p. 783). Assim, a atitude crítica requer um questionamento contínuo de si e de quem somos justamente agora: “Quem somos nós justamente agora? O que é este momento tão frágil do qual não podemos destacar nossa identidade e que nos levará com ele?" (1994a, p. 783). Nas Tanner lectures, pronunciadas em Stanford em 1979, Foucault voltará a esse tema e afirmará que a crítica é justamente a "introdução do 'Agora' enquanto categoria filosófica", ao mesmo tempo em que a crítica é também uma maneira de se perguntar: "Que somos nós? Como podemos ser nossos próprios contemporâneos?" (2015, p. 100).

Percebe-se que, desde ao menos a conferência de 1978, a concepção foucaultiana da crítica como atitude, como "virtude geral" (2015, p. 35) e como arte da desobediência refletida, exige do sujeito que ele se pense e se repense, que se coloque na vertical de si mesmo. A atitude crítica também exige que se interrogue a atualidade à qual se pertence, e, finalmente, que se tenha coragem necessária para não querer obedecer cegamente, o que não é o mesmo que relacionar crítica e desobediência em sentido estrito e absoluto. Tais demandas culminarão na exigência tardia de pensar e agir para transformar a si mesmo e aos outros, para modificar a própria conduta e a dos outros, no decurso de contracondutas e lutas transversais que procuram discernir os pontos 
frágeis que permitirão transformar e violar a própria realidade. Como argumentou Philippe Sabot, a nosso ver de maneira certeira, "Foucault sinaliza na direção de um outro tipo de relação entre poder, verdade e sujeito, na medida em que se trata de colocar no próprio sujeito uma disposição para agir e para criticar, tendo em vista transformar as condições nas quais o poder é conduzido a produzir discursos de verdade e a verdade é conduzida a tornar-se autoridade" (2012).

No texto derradeiro de 1984, "Qu'est-ce que les lumières?", Foucault finalmente relacionará a crítica com o "êthos dos Gregos", isto é, com um "modo de relação para com a atualidade; uma escolha voluntária feita por alguns; enfim, uma maneira de pensar e sentir, uma maneira também de agir e de se conduzir que, simultaneamente, marca uma pertença e se apresenta como tarefa" (1994b, p. 568). Ao final de seu caminho de pensamento, Foucault terá estabelecido uma série de sutis conexões entre a crítica, entendida como "arte da inservidão voluntária, aquela da indocilidade refletida" (2015, p. 39), e a ideia de inspiração baudelaireana acerca de uma "atitude voluntária de modernidade", pela qual o sujeito se esforça para produzir uma "transfiguração que não é uma anulação do real, mas um jogo difícil entre a verdade do real e o exercício da liberdade" (1994b, p. 570). Em suas derradeiras considerações sobre o assunto, a crítica como "atitude experimental" será definida como um "trabalho feito nos limites de nós mesmos", entendido como exercício que se põe "à prova da realidade e da atualidade, tanto para compreender quais são os pontos nos quais a mudança é possível e desejável, quanto para determinar a forma precisa que se deve dar a essa mudança" (1994 b, p. 574-575). Ao final de seu percurso, Foucault enlaçará Kant e Baudelaire ao fundir a atitude crítica e a atitude de modernidade, compreendendo a ambas como exercícios de auto-invenção de um "sujeito autônomo" (1994b, p. 571). Por certo, essa autonomia não será compreendida como dado transcendental inerente à condição do ser humano enquanto ser racional, mas sim como tarefa auto imposta pela qual alguém se põe "à prova histórico-prática dos limites que podemos ultrapassar", ação reflexiva que só pode ser entendida como "trabalho de nós mesmos sobre nós mesmos enquanto sujeitos livres" (1994 b, p. 575). Numa palavra, 
Foucault entende o trabalho da crítica como um "trabalho sobre nossos limites, isto é, um trabalho paciente e que dá forma à impaciência da liberdade" (1994 b, p. 578).

\section{Judith Butler e 0 apelo às políticas de coalizão não-identitárias}

Desde Gender Trouble (1990), Butler se propusera a questionar os pressupostos ontológicos que orientavam o feminismo e, deste modo, a dinâmica representativa que pautava suas ações e lutas. Butler considerava que a melhor maneira de conceber uma política feminista não identitária seria a formulação de uma abordagem "anti-fundacionista para a política de coalizão" (1990, p. 15), isto é, uma política de coalizão que não tenha de postular qualquer identidade como fator de unificação dos sujeitos representados por um movimento social. Tal política, portanto, não visaria estabelecer um consenso prévio sobre a identidade de um determinado conjunto de sujeitos, nem deveria almejar alcançar tal consenso em algum futuro próximo ou distante. Pelo contrário, as lutas dos movimentos políticos das minorias deveriam se organizar de maneira a associar e incluir diferentes agentes, os quais preservariam suas diferenças e distinções: “Talvez a coalizão precise reconhecer suas contradições e agir preservando intactas aquelas contradições" (1990, p. 14). Para a autora, "a divergência, a fratura, a dissensão e a fragmentação" (1990, p. 14) devem ser aceitos como intrínsecos ao processo democrático, de modo que não se deveria pretender abolir as diferenças existentes entre diferentes atores sociais. Deste modo, uma política desprovida de fundamentos identitários deve ser entendida como uma "coalizão aberta", capaz de "afirmar identidades que são alternadamente instituídas e abandonadas de acordo com as finalidades em curso; será uma reunião aberta que permita múltiplas convergências e divergências sem ter de obedecer a um telos normativo definidor e fechado" (1990, p. 16). Contra os postulados de princípio pela fragmentação ou pela unificação, entendidos como fins políticos fechados sobre si mesmos, Butler sugere que as políticas e coalizão entre grupos minoritários ou marginalizados podem dar ocasião a uniões 
transitórias em torno a questões e pautas comuns, desde que tais agentes não se encerrem no interior de definições identitárias excessivamente rígidas e de natureza essencialista.

Em Notes toward a performative theory of assembly (2015), Butler reafirma sua proposta de uma luta política por "direitos plurais", reiterando que ela não deve estar baseada na definição de identidades previamente dadas, visto que se trata, por outro lado, de fortalecer a ideia de "interdependência" relacional contra toda forma de sectarismo identitário (p. 67). O pressuposto normativo das lutas políticas pós-identitárias, que não são, evidentemente, contrárias às identidades, é o de que todas as formas de vida devem ser tratadas de maneira digna e igualitária, bem como devem ser todas igualmente vivíveis. Isto, por sua vez, exige considerar as desigualdades estruturais e socialmente induzidas no que diz respeito à partilha do sofrimento e da vulnerabilidade. Se já em Gender Trouble a autora propunha uma política de "alianças", em suas obras mais recentes tais alianças passaram a englobar todas aquelas categorias sociais sujeitas aos processos de precarização e de vulneração, para além das mulheres e da população LGBT. Se antes Butler se ocupava especificamente com as práticas e discursos de resistência do universo gay e lesbiano, em particular aqueles que podiam promover a subversão paródica das normas hegemônicas do sistema sexo-corpo-gênero-desejo, agora Butler pensa as políticas de aliança e coalizão pós-identitária como associações que ressaltam a interdependência e o caráter relacional e compartilhado de nossa subjetividade, isto é, são formas de ação que recusam as posições que se mantêm fechadas no interior de identidades definidas de maneira essencialista. Após ter abordado o problema mais amplo da precariedade a que estão expostas diversas categorias de pessoas, e mesmo populações inteiras, o problema que se coloca para Butler é o da formação de "alianças entre várias minorias ou populações consideradas descartáveis" (2015, p. 27). Para a autora, portanto, a precariedade deve ser entendida como instância normativa apta a favorecer alianças entre os/ as desprivilegiados/as, mesmo a despeito da inexistência de quaisquer laços identitários entre eles/as, e mesmo a despeito das desconfianças que possam pairar entre eles/as. Para a autora, em suma, 
Precariedade é a rubrica que reúne mulheres, queers, pessoas transgêneras, os pobres, os habilitados de modo diferente, os apátridas, mas também minorias religiosas ou étnicas: é uma condição social e econômica, mas não uma identidade (de fato, ela perpassa todas essas categorias e produz alianças potenciais entre aqueles que não se reconhecem como pertencentes uns aos outros (2015, p. 58).

À guisa de conclusão, eis que a compreensão foucaultiana da resistência como trabalho crítico e reflexivo de transformação de si e dos outros, mediado pela extrema atenção à atualidade e seus limites, se completa perfeitamente com a ideia butleriana a respeito das possíveis alianças entre diferentes grupos marcados pela precariedade e vulnerabilidade socialmente induzidas. Sem a ênfase na reflexividade ativa, e sem a devida atenção ao caráter aberto e plural das associações políticas, as quais contêm contradições e diferenciações entre seus membros, estaremos constantemente às voltas com os riscos implicados no apelo cego a formas de empoderamento (empowerment) que bem podem significar a reinstalação de novas e velhas formas de opressão. Contra a rigidez das formas de resistência que pretendem saltar para fora do jogo das relações de poder, ou que se valem das armas e estratégias violentas do oponente para derrotá-lo, cumpre recordar que a posição crítica, para Foucault, é aquela que se instala no limite e que pretende verificar até que ponto podemos e queremos ultrapassá-lo, em nome de quê. Essa atitude de atenção exigente ao real, a fim de analisar até onde ele pode ser transformado e em qual direção, exige dos/as militantes que eles/as não assumam posições excessivamente rígidas e dogmáticas. Ela requer, em suma, que não se enclausurem no interior de círculos imantados pelo princípio narcísico da identificação com o idêntico, mas que se abram para a formação de políticas de coalizão não fundadas em bases identitárias essencialistas. 


\section{Referências}

BUTLER, J. Gender Trouble Feminism and subversion of identity. Nova York: Routledge, 1990.

BUTLER, J. Notes towards a performative theory of assembly. Nova York: Routledge, 2015.

CASTRO, E. Vocabulário de Foucault. Trad. I. M. Xavier. Belo Horizonte: Ed. Autêntica, 2009.

DUARTE, A. M. Vidas em risco: crítica do presente em Heidegger, Arendt e Foucault. Rio de Janeiro: GEN/Forense Universitária, 2010.

DUARTE, A. M. "Foucault: Biopolítica e Governamentalidade." In: GLOECKNER, R. J.; FRANÇA, L. A.; RIGON, B. S. (Org.). BIOPOLÍTICAS - Estudos sobre politica, governamentalidade e violência. 1. ed. Curitiba: iEA Academia, 2015. p. 12-36.

FOUCAULT, M. Surveiller et Punir. Paris: Gallimard, 1975.

FOUCAULT, M. Histoire de la Sexualité. La volonté de Savoir. Paris: Gallimard poche, 1976.

FOUCAULT, M. Dits et Écrits. Paris: Gallimard. vol. III, 1994a.

FOUCAULT, M. Dits et Écrits. Paris: Gallimard. vol. IV, 1994b.

FOUCAULT, M. Qu'est-ce que la critique. Suivi de La Culture de soi. Paris: Vrin, 2015. HABERMAS, J. Discurso Filosófico da Modernidade. Trad. Luiz Sergio Repa e Rodnei Nascimento. São Paulo: Martins Fontes, 2000.

SABOT, P. Avec Foucault, penser la « critique ». Overblog, 2012. Disponível em: $<$ http://philippesabot.over-blog.com/article-penser-la-critique-foucault-10335 4284.html>. Acesso em : 20 fev. 2018.

Recebido: 10/02/2019

Received: 02/10/2019

Aprovado: $12 / 03 / 2019$

Approved: 03/12/2019 